\title{
Article \\ Addition of Reduced Glutathione (GSH) to Freezing Medium Reduces Intracellular ROS Levels in Donkey Sperm
}

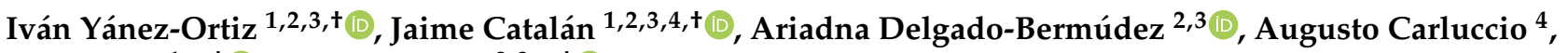 \\ Jordi Miró ${ }^{1, *, \neq(10}$ and Marc Yeste $2,3, *, \neq($ i)
}

1 Equine Reproduction Service, Department of Animal Medicine and Surgery, Faculty of Veterinary Sciences, Autonomous University of Barcelona, ES-08193 Barcelona, Cerdanyola del Vallès, Spain; ivan.yanez22@gmail.com (I.Y.-O.); dr.jcatalan@gmail.com (J.C.)

2 Biotechnology of Animal and Human Reproduction (TechnoSperm), Institute of Food and Agricultural Technology, University of Girona, ES-17003 Girona, Spain; ariadna.delgado@udg.edu

3 Unit of Cell Biology, Department of Biology, Faculty of Sciences, University of Girona, ES-17003 Girona, Spain

4 Faculty of Veterinary Medicine, University of Teramo, Loc. Piano d'Accio, IT-64100 Teramo, Italy; acarluccio@unite.it

* Correspondence: jordi.miro@uab.cat (J.M.); marc.yeste@udg.edu (M.Y.); Tel.: +34-93-5814293 (J.M.); +34-972-419514 (M.Y.)

+ These authors contributed equally to this work.

$\ddagger$ These authors share senior authorship.

Citation: Yánez-Ortiz, I.; Catalán, J.; Delgado-Bermúdez, A.; Carluccio, A.; Miró, J.; Yeste, M. Addition of Reduced Glutathione (GSH) to Freezing Medium Reduces Intracellular ROS Levels in Donkey Sperm. Vet. Sci. 2021, 8, 302. https:// doi.org/10.3390/vetsci8120302

Academic Editor: Bartosz Kempisty

Received: 5 November 2021

Accepted: 30 November 2021

Published: 2 December 2021

Publisher's Note: MDPI stays neutral with regard to jurisdictional claims in published maps and institutional affiliations.

Copyright: (c) 2021 by the authors. Licensee MDPI, Basel, Switzerland. This article is an open access article distributed under the terms and conditions of the Creative Commons Attribution (CC BY) license (https:/ / creativecommons.org/licenses/by/ $4.0 /)$.
Abstract: In donkeys, the use of frozen-thawed sperm for artificial insemination (AI) leads to low fertility rates. Furthermore, donkey sperm produce a large amount of reactive oxygen species (ROS), and post-AI inflammation induces the formation of neutrophil extracellular traps (NETosis), which further generates many more ROS. These high ROS levels may induce lipid peroxidation in the sperm plasma membrane, thus affecting its integrity. Enzymatic and non-enzymatic antioxidants, mainly found in the seminal plasma (SP), are responsible for maintaining the redox balance. However, this fluid is removed prior to cryopreservation, thereby exposing sperm cells to further oxidative stress. The exogenous addition of antioxidants to the freezing medium can reduce the detrimental effects caused by ROS generation. Therefore, the aim of this study was to evaluate how the addition of different reduced glutathione (GSH) concentrations (control, $2 \mathrm{mM}, 4 \mathrm{mM}, 6 \mathrm{mM}, 8 \mathrm{mM}$, and $10 \mathrm{mM}$ ) to fresh sperm affect their cryotolerance. Total and progressive motility, kinematic parameters and motile sperm subpopulations were significantly $(p<0.05)$ different from the control in treatments containing $8 \mathrm{mM}$ and $10 \mathrm{mM} \mathrm{GSH}$, but not at lower concentrations. Plasma and acrosome membrane integrity, mitochondrial membrane potential (MMP) and intracellular superoxide levels $\left(\mathrm{O}_{2}{ }^{-}\right)$were not affected $(p>0.05)$ by any GSH concentration. Interestingly, however, the addition of $8 \mathrm{mM}$ or $10 \mathrm{mM}$ GSH reduced $(p<0.05)$ the percentages of viable sperm with high overall ROS levels compared to the control. In conclusion, frozen-thawed donkey sperm are able to tolerate high GSH concentrations, which differs from what has been observed in other species. This antioxidant capacity suggests that ROS could be important during post-AI and that the impact of using exogenous antioxidants like GSH to improve the sperm resilience to freeze-thawing is limited in this species.

Keywords: sperm cryopreservation; reactive oxygen species (ROS); superoxide anion $\left(\mathrm{O}_{2}{ }^{-}\right)$; reduced glutathione (GSH); antioxidants; donkey

\section{Introduction}

The cryopreservation of genetic material is a milestone for reproductive biotechnology, not only in humans but also in other vertebrates [1], since it may be applied together with other assisted reproductive technologies (ART) for the dissemination of genes of genetically superior animals [2], as well as for the conservation of biodiversity and the protection of endangered species [3]. This last aspect is very relevant in the donkey because the size 
of the population has suffered a significant decrease in recent years [4], which directly affects the genetic variability of the existing breeds [5]. Research in this species has focused its efforts on improving sperm cryopreservation protocols, precisely to try to safeguard endangered donkey breeds [6-18]. However, the use of cryopreserved donkey sperm has been limited by the low conception rates obtained when jennies are inseminated $[7,8,19]$. This, which contrasts with the reproductive performance of mares, is largely due to the physiological endometritis that occurs in the jenny after artificial insemination (AI) [20,21].

In addition to the above, cryopreservation is known to induce freezing injuries in sperm due to their exposure to thermal and osmotic stresses and their high sensitivity to an oxidative environment, which leads to subsequent lipid peroxidation in the plasma membrane [22]. In the particular case of donkey sperm, and in a similar fashion to other species, this occurs because the plasma membrane contains a large amount of polyunsaturated fatty acids esterified into phospholipids [23]. Oxidative stress can be defined as a consequence of the imbalance between the cellular antioxidant defense system and the production of reactive oxygen species (ROS). Physiologically, sperm release ROS as a by-product of their metabolism; these ROS are scavenged by enzymatic and non-enzymatic antioxidants which play an instrumental role in maintaining the redox balance [24]. Both types of antioxidants, whose function is to prevent oxidative damage, are present in sperm or in seminal plasma (SP) [25]. In this context, it is worth mentioning that Papas et al. [26] showed that the antioxidant capacity of the enzymes present in the SP is significantly higher in donkeys than in horses. In spite of this, the sperm cryopreservation protocols currently applied in donkeys include the elimination of SP by centrifugation [27]. This makes sperm more susceptible to functional damage with lethal consequences [28] and lead them to undergo structural injuries, mainly at the chromatin level, which has a significant impact on male fertility [29]. In addition, it must be considered that, in equids, the presence of sperm during AI causes a powerful endometrial reaction with a large influx of polymorphonuclear neutrophils (PMN) into the uterine lumen [20,30-32]. These polymorphonuclear neutrophils act mainly via degranulating/extruding their DNA and bactericidal molecules (histones and enzymes), thereby forming neutrophil extracellular traps (NETs) that capture sperm without killing them [33]. Therefore, sperm:PMN binding in donkey activates one of the defense mechanisms of polymorphonuclear neutrophils, NETosis [34], which releases a large amount of ROS. These ROS levels are much greater than those generated by sperm [35] and even by the polymorphonuclear neutrophils themselves [36].

An alternative to counteract the negative effect that ROS generates on sperm from different mammalian species, including the human [37], is the addition of reduced glutathione (GSH) to the preservation medium in both cooling [38-41] and freezing [42-46]. Reduced glutathione is one of the most relevant non-enzymatic antioxidants in mammalian cells, and most of its scavenging effect results from the interaction with glutathione reductase (GSR) and glutathione peroxidase (GPX) [47]. Reduced glutathione contains a sulfhydryl group (-SH) that protects the disulfide bonds between chromatin fibers from the oxidative damage caused by ROS, thus maintaining the sperm nuclear structure during cryopreservation [47-49].

Despite the antioxidant properties of GSH to maintain the redox balance during cryopreservation, GSH concentrations greater than $2.5 \mathrm{mM}$ have been found to be toxic to horse sperm when added to the freezing extender, as there is a significant reduction in the motility, viability and plasma membrane integrity after thawing [43]. The same effect has been observed in pigs, as the addition of $1 \mathrm{mM} \mathrm{GSH}$ to the freezing medium results in greater protection of sperm function than higher concentrations [41]. In donkeys, there is only one study that investigated the effects of supplementing the freezing medium with GSH; however, only one concentration was tested [16]. Testing the resilience of donkey sperm to oxidative stress using different GSH concentrations could shed some light into the reproductive strategy of this species [50-52]. In addition, supplementing freezing media with GSH could improve donkey sperm function and survival after thawing, which would help sperm to fight against the oxidative environment they encounter when reaching the 
jenny uterus after AI [20]. Therefore, the objective of this study was to evaluate how different GSH concentrations added to the freezing medium affect the cryotolerance of donkey sperm.

\section{Materials and Methods}

\subsection{Donkeys and Sperm Samples}

A total of 12 ejaculates from 4 adult Catalonian jackasses (age: between 3 and 6 years old) were used. Animals were clinically healthy and of proven fertility (good fertility rates), and were maintained in individual paddocks at the Equine Reproduction Service, Autonomous University of Barcelona (Bellaterra, Cerdanyola del Vallès, Spain). This is a center for the collection of semen from equids that holds an EU approval (authorization number: ES09RS01E) and operates under rigorous protocols which include the control of the health and welfare of animals. Thus, it was not necessary to receive a specific approval from the Ethics Committee of the Autonomous University of Barcelona (Bellaterra, Cerdanyola del Vallès, Spain) to handle animals, since the four jackasses were semen donors. Complying with the sanitary guidelines established by the Council of the European Communities in Directive 82/894/EEC of 21 December 1982, animals were free of equine viral arteritis, equine infectious anemia and equine contagious metritis.

Sperm collection was performed on a regular schedule in the morning through an artificial vagina (Hannover model; Minitüb GmbH, Tiefenbach, Germany) with the use of an in-line nylon filter to remove the gel fraction. Once the ejaculate was obtained, it was immediately diluted 1:5 (v:v) in a skim milk-based extender [53], prewarmed to $37^{\circ} \mathrm{C}$. The quality of fresh sperm was checked through the analysis of concentration (Neubauer chamber; Paul Marienfeld GmbH \& Co. KG, Lauda-Königshofen, Germany), motility (CASA system; see Section 2.5 for details), and viability and morphology (eosin-nigrosin staining; see Section 2.6 for details). All samples were confirmed to be above the standard thresholds before freezing: viable sperm $\geq 85 \%$, morphologically normal sperm $\geq 70 \%$, and total motile sperm $\geq 80 \%$.

\subsection{Experimental Design}

Before cryopreservation, each diluted sperm sample was centrifuged at $600 \times g$ and $20^{\circ} \mathrm{C}$ for $15 \mathrm{~min}$ (Medifriger BL-S; JP Selecta SA, Barcelona, Spain); the supernatant was discarded and the pellet was resuspended in a commercial freezing medium containing glycerol and methylformamide as permeable cryoprotectants (BotuCRIO; Botupharma Animal Biotechnology, Botucatu, Brazil). Subsequently, sperm concentration and viability were again analyzed, and the same freezing medium (BotuCRIO) was added to obtain a final concentration of $200 \times 10^{6}$ viable sperm $/ \mathrm{mL}$ (normalized in all cases). The final volume was divided into 6 aliquots of $3 \mathrm{~mL}$ each, and a different concentration of reduced glutathione (GSH; G4251; Saint Louis, MO, USA; final concentrations: 2 mM, 4 mM, 6 mM, $8 \mathrm{mM}$, and $10 \mathrm{mM}$ ) was added; the control was not supplemented with GSH. A total of 6 separate $0.5 \mathrm{~mL}$ plastic straws were filled with the content of each aliquot (sperm sample with its respective treatment). Each straw was manually labeled with the freezing date, jackass name and treatment as follows: T1 $=$ sperm (control); T2 $=$ sperm $+2 \mathrm{mM} \mathrm{GSH}$; $\mathrm{T} 3=$ sperm $+4 \mathrm{mM} \mathrm{GSH} ; \mathrm{T} 4=$ sperm $+6 \mathrm{mM} \mathrm{GSH} ; \mathrm{T} 5=$ sperm $+8 \mathrm{mM} \mathrm{GSH}$; and T6 = sperm + $10 \mathrm{mM} \mathrm{GSH}$.

\subsection{Sperm Cryopreservation}

All straws were cryopreserved in parallel using an automatic controlled-rate freezer (Ice-Cube 14S; Minitüb GmbH, Tiefenbach, Germany). Cooling/freezing was carried out in 3 stages: (1) cooling from $20^{\circ} \mathrm{C}$ to $5^{\circ} \mathrm{C}$ for $60 \mathrm{~min}$ at a rate of $-0.25^{\circ} \mathrm{C} / \mathrm{min}$, (2) freezing from $5{ }^{\circ} \mathrm{C}$ to $-90{ }^{\circ} \mathrm{C}$ for $20 \mathrm{~min}$ at a rate of $-4.75^{\circ} \mathrm{C} / \mathrm{min}$, and (3) freezing from $-90^{\circ} \mathrm{C}$ to $-120^{\circ} \mathrm{C}$ for $2.7 \mathrm{~min}$ at a rate of $-11^{\circ} \mathrm{C} / \mathrm{min}$. Finally, straws were plunged into liquid nitrogen at $-196^{\circ} \mathrm{C}$ and stored in appropriate tanks for their conservation until analysis. 


\subsection{Sperm Thawing}

Frozen sperm straws were thawed by incubation at $37^{\circ} \mathrm{C}$ for $30 \mathrm{~s}$ in a hot water bath. The content of each straw was poured into a $10-\mathrm{mL}$ conical tube for post-thaw sperm analysis. For each treatment and sperm sample, one straw was used for the assessment of motility (CASA system; see Section 2.5 for more details) and viability (eosin-nigrosin staining; see Section 2.6 for more details), and the other two were utilized for the evaluation of sperm parameters through flow cytometry (see Section 2.7 for details).

\subsection{Sperm Motility Analysis}

Sperm motility was evaluated by means of a CASA-Mot module of the ISAS v1.2 system (Proiser R + D, Valencia, Spain) equipped with a high-resolution digital camera model MQ003MG-CM (Proiser R + D, Valencia, Spain) capable of capturing up to 100 frames per second (fps). Before doing so, the content of each straw was diluted 1:2 (v:v) in a cooling extender based on skim milk prewarmed to $38^{\circ} \mathrm{C}[53,54]$. Briefly, $2 \mu \mathrm{L}$ of each sperm sample was placed into a reusable Spermtrack10 chamber (Spk 10; Proiser R + D, Valencia, Spain), prewarmed to $38^{\circ} \mathrm{C}$. A minimum of 500 spermatozoa were counted per analysis under a $10 \times$ negative phase contrast microscope model UOP200i (Proiser R + D, Valencia, Spain). Total (TM, \%) and progressive sperm motility (PM, \%) were evaluated together regarding the following kinematic parameters: curvilinear velocity $(\mathrm{VCL}, \mu \mathrm{m} / \mathrm{s}$ ), straight line velocity (VSL, $\mu \mathrm{m} / \mathrm{s}$ ), average path velocity (VAP, $\mu \mathrm{m} / \mathrm{s}$ ), linearity coefficient $(\mathrm{LIN}=[\mathrm{VSL} / \mathrm{VCL}] \times 100, \%)$, straightness coefficient $(\mathrm{STR}=[\mathrm{VSL} / \mathrm{VAP}] \times 100, \%)$, wobble coefficient $(\mathrm{WOB}=[\mathrm{VAP} / \mathrm{VCL}] \times 100, \%)$, amplitude of lateral head displacement $(\mathrm{ALH}, \mu \mathrm{m})$, and beat-cross frequency $(\mathrm{BCF}, \mathrm{Hz})$. The CASA-Mot settings were those recommended by the manufacturer: particle area $>4$ and $<75 \mu \mathrm{m}^{2}$, connectivity: 6 , minimum number of images to calculate ALH: 10 . VAP $\geq 10 \mu \mathrm{m} / \mathrm{s}$ and STR $\geq 75 \%$ were used as cut-off values for motile sperm and progressively motile sperm, respectively. Three technical replicates were examined.

\subsection{Sperm Viability Analysis}

Sperm viability was analyzed by eosin-nigrosin staining [55]. Briefly, $10 \mu \mathrm{L}$ of the content of each sperm sample was placed on a slide which was previously preheated to $37^{\circ} \mathrm{C}$. Immediately afterwards, $10 \mu \mathrm{L}$ of the eosin-nigrosin stain was placed onto the sperm sample and mixed; the mixture was smeared. A bright field light microscope (Carl Zeiss, Göttingen, Germany) at $1000 \times$ magnification using immersion oil objective was used to evaluate a minimum of 200 sperm/sample. The percentage of viable sperm (eosin negative) was recorded and three technical replicates were evaluated.

\subsection{Evaluation of Sperm through Flow Cytometry}

The sperm functional parameters evaluated through flow cytometry were plasma membrane integrity (SYBR-14/PI), acrosome membrane integrity (PNA-FITC/PI), mitochondrial membrane potential (MMP, JC- 1$)$, intracellular ROS levels $\left(\mathrm{H}_{2} \mathrm{DCFDA} / \mathrm{PI}\right)$, and intracellular superoxides levels (HE/YO-PRO-1). Fluorochromes were purchased from Molecular Probes (Thermo Fisher Scientific, Waltham, MA, USA). Sperm concentration was adjusted to $1 \times 10^{6}$ sperm $/ \mathrm{mL}$ before staining. For each sample, a total of 10,000 events were analyzed, and 3 technical replicates were evaluated.

A CytoFLEX flow cytometer (Beckman Coulter Fullerton, CA, USA) was used with a sheath flow rate set at $10 \mu \mathrm{L} / \mathrm{min}$. Samples were excited with an argon ion laser (488 $\mathrm{nm}$ ) at a power of $50 \mathrm{~mW}$. Cell diameter/volume was assessed through the Coulter principle. To exclude cell aggregates and debris, distributions of two different dot plots were used. Cell aggregates were excluded on the basis of forward scatter height (FSC-H) and altitude (FSC-A) dot plot distribution, whereas subcellular debris were excluded based on the distribution of FSC-A and side scatter altitude (SSC-A) dot plots.

A total of 3 different optical filters were used: FITC was used for the analysis of SYBR-14, PNA-FITC, JC-1 monomers (JC-1 mon), DCF ${ }^{+}$and YO-PRO-1 (band pass: 525-540 nm); PE for 
the analysis of JC- 1 aggregates (JC- $1_{\mathrm{agg}}$ ) and $\mathrm{E}^{+}$(band pass: $585-542 \mathrm{~nm}$ ), and PC5.5 for PI analysis (band pass: 690-650 nm). Information about each event (FSC-A, FSC-H, SSC-A, FITC, $\mathrm{PE}$, and PC5.5) was collected in xit files and quantification from each sperm population was obtained using the CytExpert analysis software (Beckman Coulter Fullerton, CA, USA). The analyses were performed following the recommendations of the International Society for the Advancement of Cytometry (ISAC) [56]. For each parameter, the corresponding mean and standard error of the mean (SEM) were calculated.

\subsubsection{Plasma Membrane Integrity Analysis (SYBR-14/PI)}

The analysis of plasma membrane integrity was carried out following the protocol described by Garner and Johnson [57], adapted to donkey sperm, using the LIVE/DEAD sperm viability kit (SYBR-14/PI). Briefly, sperm samples were incubated in the dark at $38{ }^{\circ} \mathrm{C}$ with SYBR-14 (final concentration: $31.8 \mathrm{nM}$ ) for $10 \mathrm{~min}$ and PI (final concentration: $7.6 \mu \mathrm{M}$ ) for a further $5 \mathrm{~min}$. Three sperm populations were identified: (1) sperm with an intact plasma membrane, green-stained (SYBR-14 $\left.{ }^{+} / \mathrm{PI}^{-}\right),(2)$ sperm with a damaged plasma membrane, red-stained (SYBR-14 $\left.{ }^{-} / \mathrm{PI}^{+}\right)$, and (3) sperm with a damaged plasma membrane, both green- and red-stained (SYBR- $\left.14^{+} / \mathrm{PI}^{+}\right)$. The unstained sperm (SYBR-14- $/ \mathrm{PI}^{-}$) were considered as non-sperm particles (debris) and were used to correct the data in the other evaluations. The spill over of SYBR-14 in the PC5.5 channel (8.34\%) was compensated.

\subsubsection{Acrosome Membrane Integrity Analysis (PNA-FITC/PI)}

The integrity of the acrosome membrane was evaluated following the protocol described by Rathi et al. [58] adapted to donkey sperm using PNA-FITC and PI. Briefly, sperm samples were incubated in the dark at $38^{\circ} \mathrm{C}$ with FITC-conjugated PNA (final concentration: $1.17 \mu \mathrm{g} / \mathrm{mL}$ ) and PI (final concentration: $5.6 \mu \mathrm{m}$ ) for $10 \mathrm{~min}$. Four sperm populations were identified: (1) sperm with an intact plasma membrane (PNA-FITC $\left.{ }^{-} / \mathrm{PI}^{-}\right)$, (2) sperm with a damaged plasma membrane that presented an acrosomal membrane that could not be completely intact (PNA-FITC ${ }^{+} / \mathrm{PI}^{+}$), (3) sperm with a damaged plasma membrane and missing outer acrosomal membrane (PNA-FITC $-/ \mathrm{PI}^{+}$), and (4) sperm with a damaged plasma membrane (PNA-FITC ${ }^{+} / \mathrm{PI}^{-}$). Data were not compensated.

\subsubsection{Mitochondrial Membrane Potential (MMP) Analysis (JC-1)}

The MMP analysis was performed following the protocol described by Ortega-Ferrusola et al. [59] adapted to donkey sperm using JC-1 iodide (5.5' , 6, $6^{\prime}$-tetrachloro$1,1^{\prime}, 3,3^{\prime}$ tetraethylbenzimidazolylcarbocyanine). In brief, sperm samples were incubated in the dark at $38^{\circ} \mathrm{C}$ for 30 min with JC-1 (final concentration: $750 \mathrm{nM}$ ). In the presence of low MMP, JC-1 molecules remain as green-fluorescent monomers (JC-1 mon), whereas in the presence of high MMP, they form orange-fluorescent aggregates (JC- $1_{\mathrm{agg}}$ ). Two sperm populations were distinguished: (1) low MMP sperm (cells presenting a JC-1 mon fluorescence intensity higher than a JC-1 agg fluorescence intensity) and (2) high MMP sperm (cells presenting a JC-1 agg fluorescence intensity higher than a JC $-1_{\text {mon }}$ fluorescence intensity). Data were not compensated. The fluorescence intensity of JC-1 mon and JC-1 agg was recorded in all sperm populations, and the ratio between $\mathrm{JC}-1_{\text {agg }}$ and $\mathrm{JC}-1_{\text {mon }}$ was calculated.

2.7.4. Intracellular Reactive Oxygen Species (ROS) Levels Analysis: $\mathrm{H}_{2} \mathrm{O}_{2}\left(\mathrm{H}_{2}\right.$ DCFDA/PI) and $\mathrm{O}_{2}^{-}$(HE/YO-PRO-1)

The analysis of the intracellular levels of ROS was carried out following the protocol described by Morrell et al. [60] and Guthrie and Welch [61], adapted to donkey sperm. The combination of $2^{\prime}, 7^{\prime}$-dichlorodihydrofluorescein diacetate $\left(\mathrm{H}_{2} \mathrm{DCFDA}\right)$ and PI was used to measure overall intracellular ROS levels, and the combination of hydroetidine (HE) and YO-PRO-1 was used to measure intracellular levels of superoxide anion $\left(\mathrm{O}_{2}{ }^{-}\right)$.

For ROS evaluation, sperm samples were incubated in the dark at $38^{\circ} \mathrm{C}$ with $\mathrm{H}_{2} \mathrm{DCFDA}$ (final concentration: $50 \mu \mathrm{M}$ ) for $20 \mathrm{~min}$; thereafter, PI (final concentration: $6 \mu \mathrm{M}$ ) was added and samples were incubated for $5 \mathrm{~min}$. In the presence of ROS, $\mathrm{H}_{2}$ DCFDA is de-esterified 
and oxidized into the highly fluorescent molecule $\mathrm{DCF}^{+}$. Therefore, four sperm populations were identified: (1) viable sperm with high ROS levels $\left(\mathrm{DCF}^{+} / \mathrm{PI}^{-}\right)$, (2) non-viable sperm with high ROS levels $\left(\mathrm{DCF}^{+} / \mathrm{PI}^{+}\right)$, (3) viable sperm with low ROS levels $\left(\mathrm{DCF}^{-} / \mathrm{PI}^{-}\right)$, and (4) non-viable sperm with low ROS levels $\left(\mathrm{DCF}^{-} / \mathrm{PI}^{+}\right)$. Data were not compensated. The fluorescence intensity of $\mathrm{DCF}^{+}$was recorded in all sperm populations.

For the measurement of the intracellular levels of $\mathrm{O}_{2}{ }^{-}$, sperm samples were incubated in the dark at $38{ }^{\circ} \mathrm{C}$ with $\mathrm{HE}$ (final concentration: $5 \mu \mathrm{M}$ ) and with YO-PRO-1 (final concentration: $31.25 \mathrm{nM}$ ) for $30 \mathrm{~min}$. In the presence of $\mathrm{O}_{2}{ }^{-}, \mathrm{HE}$ is oxidized into fluorescent ethidium $\left(\mathrm{E}^{+}\right)$. This allowed the observation of four sperm populations: (1) viable sperm with high $\mathrm{O}_{2}{ }^{-}$levels $\left(\mathrm{E}^{+} / \mathrm{YO}-\mathrm{PRO}-1^{-}\right)$, (2) non-viable sperm with high $\mathrm{O}_{2}{ }^{-}$levels $\left(\mathrm{E}^{+} / \mathrm{YO}-\right.$ PRO- $\left.1^{+}\right)$, (3) viable sperm with low. $\mathrm{O}_{2}{ }^{-}$levels $\left(\mathrm{E}^{-} / \mathrm{YO}-\mathrm{PRO}-1^{-}\right)$, and (4) non-viable sperm with low $\mathrm{O}_{2}{ }^{-}$levels $\left(\mathrm{E}^{-} / \mathrm{YO}-\mathrm{PRO}-1^{+}\right)$. The spill over of $\mathrm{E}^{+}$into the FITC channel (3.62\%) was compensated. The fluorescence intensity of $\mathrm{E}^{+}$was recorded in all sperm populations.

\subsection{Statistical Analyses}

Statistical analyses were performed with the R statistical package (V 4.0.3, R Core Team; Vienna, Austria) and graphs were plotted with GraphPad Prism (V 8.4.0, GraphPad Software LLC; San Diego, CA, USA). The Shapiro-Wilk test was run to verify the normal distribution of data and the Levene test checked the homoscedasticity. When necessary, data were transformed with arcsin $\sqrt{ } \mathrm{x}$ to match with parametric assumptions. When these assumptions were not met, a non-parametric analysis was performed using the Kruskal-Wallis test followed by the Wilcoxon test $(p \leq 0.05)$ for pairwise comparisons. The effects of the different GSH concentrations (control, $2 \mathrm{mM}, 4 \mathrm{mM}, 6 \mathrm{mM}, 8 \mathrm{mM}$, and $10 \mathrm{mM}$ ) on motility, viability (eosin-nigrosin), plasma membrane integrity $\left(\mathrm{SYBR}^{+} 4^{+} / \mathrm{PI}^{-}\right)$, acrosome membrane integrity (PNA-FITC $\left.{ }^{-} / \mathrm{PI}^{-}\right)$, MPP $\left(\mathrm{JC}-1_{\text {agg }}\right.$ ), intracellular $\mathrm{H}_{2} \mathrm{O}_{2}$ levels $\left(\mathrm{DCF}^{+} / \mathrm{PI}^{-}\right)$, and intracellular $\mathrm{O}_{2}^{-}$levels $\left(\mathrm{E}^{+} / \mathrm{YO}-\mathrm{PRO}-1^{-}\right)$, as well as the geometric mean of fluorescence intensity (GMFI) of JC- $1_{\mathrm{agg}}, \mathrm{DCF}^{+}$and $\mathrm{E}^{+}$after thawing, were analyzed using a one-way ANOVA, followed by the Bonferroni post-hoc test $(p \leq 0.05)$ for pairwise comparisons.

Motile sperm subpopulations were obtained by applying the procedure described by Martí et al. [62]. Briefly, a principal component analysis (PCA) was performed from the kinematic parameters (VCL, VSL, VAP, LIN, STR, WOB, ALH, and BCF) of each sperm cell after thawing. The matrix obtained was rotated using the Varimax method with Kaiser normalization, where each spermatozoon was assigned a regression score. These values were used to perform a non-hierarchical, multivariate cluster analysis using the $k$-means model based on Euclidean distances. Finally, the proportion of spermatozoa in each subpopulation was calculated to analyze the effects of the different GSH concentrations through a one-way ANOVA, followed by the Bonferroni post-hoc test $(p \leq 0.05)$ for pairwise comparisons.

In all analyses, the results are expressed as means \pm SEM.

\section{Results}

\subsection{Sperm Motility}

The percentage of total motile sperm at post-thaw (Figure 1A) was significantly lower in the treatments containing $8 \mathrm{mM} \mathrm{GSH}(29.36 \% \pm 6.88 \%)$ and $10 \mathrm{mM} \mathrm{GSH}(7.85 \% \pm 3.10 \%)$ than in the control $(62.56 \% \pm 4.81 \%)$ and those containing $2 \mathrm{mM} \mathrm{GSH}(59.18 \% \pm 5.42 \%)$ and $4 \mathrm{mM} \mathrm{GSH}(57.20 \% \pm 5.50 \%)$. The concentration of $6 \mathrm{mM} \mathrm{GSH}(47.81 \% \pm 6.36 \%)$ only differed from that of $10 \mathrm{mM}(p<0.05)$. In addition, the percentage of progressively motile sperm (Figure 1B) decreased significantly when GSH concentrations of $8 \mathrm{mM}(9.76 \% \pm 3.95 \%)$ and $10 \mathrm{mM}(1.65 \% \pm 0.96 \%)$ were added, compared to the control $(34.05 \% \pm 4.61 \%), 2 \mathrm{mM} \mathrm{GSH}(37.20 \% \pm 5.04 \%)$ and $4 \mathrm{mM} \mathrm{GSH}(31.41 \% \pm 5.30 \%)$. The concentration of $6 \mathrm{mM}(27.14 \% \pm 5.70 \%)$ was only different from that of $10 \mathrm{mM}(p<0.05)$. 


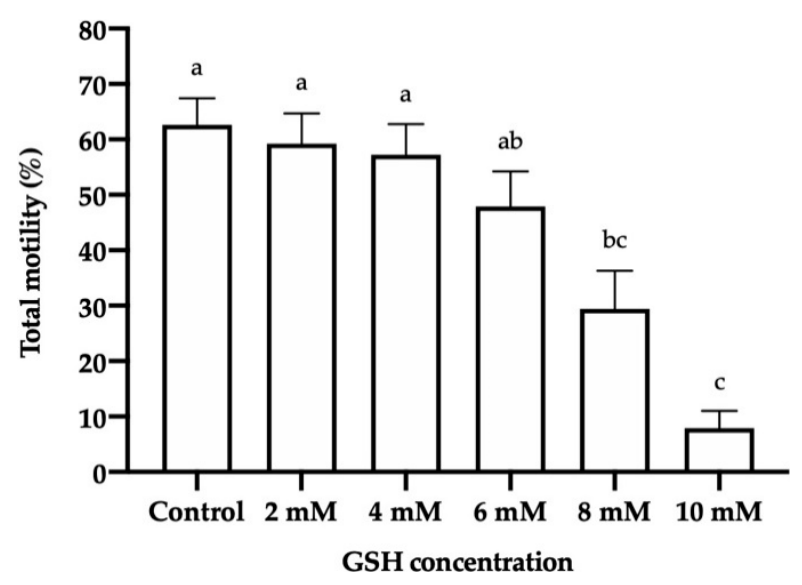

(A)

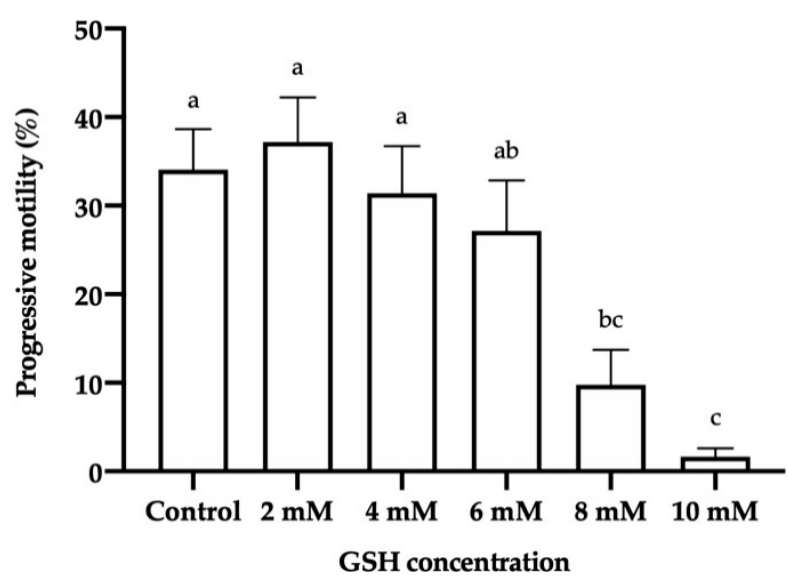

(B)

Figure 1. Mean \pm SEM of the total (A) and progressive (B) motility of frozen-thawed donkey sperm following cryopreservation with different reduced glutathione $(\mathrm{GSH})$ concentrations. $(\mathrm{a}-\mathrm{c})$ Different letters indicate significant differences $(p \leq 0.05)$ between the control and GSH treatments.

On the other hand, the kinematic parameters of frozen-thawed donkey sperm remained without significant changes at concentrations $\leq 6 \mathrm{mM}$ GSH compared to the control (Table 1). Indeed, VCL, VAP, WOB and ALH were significantly lower in the treatment containing $10 \mathrm{mM}$ than in the control $(p<0.05)$, whereas VSL, LIN, STR, and BCF were lower than the control in those having $8 \mathrm{mM}$ and $10 \mathrm{mM} \mathrm{GSH}(p<0.05)$.

Table 1. Mean \pm SEM of the kinematic parameters of frozen-thawed donkey sperm following cryopreservation with different reduced glutathione (GSH) concentrations.

\begin{tabular}{ccccccc}
\hline \multirow{2}{*}{ Parameter } & Control & $\mathbf{2 ~} \mathbf{~ m M}$ & $\mathbf{4} \mathbf{~ G M}$ & $\mathbf{6} \mathbf{~ m M}$ & $\mathbf{8} \mathbf{~ m M}$ & $\mathbf{1 0} \mathbf{~ m M}$ \\
\hline VCL $(\mu \mathrm{m} / \mathrm{s})$ & $134.66 \pm 8.53^{\mathrm{a}}$ & $152.04 \pm 6.74^{\mathrm{a}}$ & $139.16 \pm 7.43^{\mathrm{a}}$ & $138.69 \pm 9.47^{\mathrm{a}}$ & $114.97 \pm 13.76^{\mathrm{a}}$ & $57.03 \pm 18.80^{\mathrm{b}}$ \\
VSL $(\mu \mathrm{m} / \mathrm{s})$ & $53.16 \pm 4.55^{\mathrm{a}}$ & $60.51 \pm 4.09^{\mathrm{a}}$ & $52.71 \pm 4.11^{\mathrm{a}}$ & $50.47 \pm 5.20^{\mathrm{a}}$ & $30.14 \pm 4.76^{\mathrm{b}}$ & $13.53 \pm 5.08^{\mathrm{b}}$ \\
VAP $(\mu \mathrm{m} / \mathrm{s})$ & $69.42 \pm 4.75^{\mathrm{a}}$ & $76.22 \pm 3.75^{\mathrm{a}}$ & $70.92 \pm 2.98^{\mathrm{a}}$ & $68.26 \pm 4.51^{\mathrm{a}}$ & $53.05 \pm 5.95^{\mathrm{a}}$ & $27.23 \pm 8.54^{\mathrm{b}}$ \\
LIN $(\%)$ & $37.02 \pm 1.20^{\mathrm{a}}$ & $37.96 \pm 1.26^{\mathrm{a}}$ & $35.59 \pm 1.29^{\mathrm{a}}$ & $33.96 \pm 1.67^{\mathrm{a}}$ & $23.06 \pm 2.61^{\mathrm{b}}$ & $10.98 \pm 3.75^{\mathrm{c}}$ \\
STR $(\%)$ & $70.07 \pm 1.91^{\mathrm{a}}$ & $74.07 \pm 2.09^{\mathrm{a}}$ & $68.06 \pm 3.21^{\mathrm{a}}$ & $67.37 \pm 3.21^{\mathrm{a}}$ & $47.72 \pm 5.40^{\mathrm{b}}$ & $23.19 \pm 7.92^{\mathrm{c}}$ \\
WOB $(\%)$ & $51.61 \pm 0.39^{\mathrm{a}}$ & $50.65 \pm 0.65^{\mathrm{a}}$ & $51.96 \pm 1.50^{\mathrm{a}}$ & $49.95 \pm 0.88^{\mathrm{a}}$ & $44.14 \pm 4.51^{\mathrm{a}}$ & $24.70 \pm 7.55^{\mathrm{b}}$ \\
ALH $(\mu \mathrm{m})$ & $1.81 \pm 0.08^{\mathrm{a}}$ & $2.06 \pm 0.08^{\mathrm{a}}$ & $1.92 \pm 0.10^{\mathrm{a}}$ & $1.93 \pm 0.11^{\mathrm{a}}$ & $1.62 \pm 0.18^{\mathrm{a}}$ & $0.83 \pm 0.27^{\mathrm{b}}$ \\
BCF $(\mathrm{Hz})$ & $28.23 \pm 2.28^{\mathrm{a}}$ & $29.27 \pm 2.19^{\mathrm{a}}$ & $25.84 \pm 1.46^{\mathrm{a}}$ & $23.57 \pm 1.91^{\mathrm{ab}}$ & $15.19 \pm 1.90^{\mathrm{bc}}$ & $8.05 \pm 2.52^{\mathrm{c}}$ \\
\hline
\end{tabular}

VCL $(\mu \mathrm{m} / \mathrm{s})$ : curvilinear velocity; VSL $(\mu \mathrm{m} / \mathrm{s})$ : straight line velocity; VAP $(\mu \mathrm{m} / \mathrm{s})$ : average path velocity; LIN (\%): linearity coefficient; STR (\%): straightness coefficient; WOB (\%): wobble coefficient; ALH $(\mu \mathrm{m})$ : amplitude of lateral head displacement; BCF (Hz): beat-cross frequency. $\left({ }^{\mathrm{a}-\mathrm{c}}\right)$ Different letters indicate significant differences $(p \leq 0.05)$ between the control and GSH treatments.

\subsection{Motile Sperm Subpopulations}

Four motile sperm subpopulations were identified in frozen-thawed donkey sperm (Table 2). Subpopulation 1 (SP1) was characterized by being the fastest (higher values of VCL, VSL, and VAP) and most progressive (high values of LIN, STR, ALH and BCF, although WOB was intermediate). Subpopulation 2 (SP2) was the slowest and least progressive, with the lowest ALH and BCF values. Subpopulation 3 (SP3) presented intermediate velocity and progressivity values similar to those of SP1, with an intermediate ALH and a BCF similar to SP1. Finally, subpopulation 4 (SP4) was also characterized by presenting intermediate speed, progressivity values, $\mathrm{ALH}$ and $\mathrm{BCF}$. Although these parameters were lower than in SP1 and SP3, SP4 exhibited the highest WOB.

The proportions of motile spermatozoa of SP2 identified in frozen-thawed donkey sperm (Figure 2) were significantly higher in the presence of $8 \mathrm{mM}(53.65 \% \pm 7.10 \%)$ and $10 \mathrm{mM} \mathrm{GSH}(79.04 \% \pm 9.01 \%)$ than in that of $2 \mathrm{mM} \mathrm{GSH}(24.56 \% \pm 3.37 \%)$. On the contrary, SP3 reduced its proportion in the presence of $8 \mathrm{mM}(12.88 \% \pm 3.34 \%)$ and $10 \mathrm{mM}$ 
GSH $(7.24 \% \pm 4.66 \%)$ compared to $2 \mathrm{mM} \mathrm{GSH}(29.87 \% \pm 2.77 \% ; p<0.05)$. Similarly, the proportion of sperm belonging to SP1 was significantly lower in the treatment containing $10 \mathrm{mM}$ GSH than in that with $2 \mathrm{mM} \mathrm{GSH}(0.72 \% \pm 0.58 \%$ vs. $11.52 \% \pm 2.28 \%)$, and the proportion of SP4-sperm was lower in the presence of $10 \mathrm{mM} \mathrm{GSH}(13.01 \% \pm 4.92 \%)$ than in the control $(34.05 \% \pm 1.83 \%)$ and treatments with $2 \mathrm{mM}(34.11 \% \pm 1.42 \%), 4 \mathrm{mM}$ $(33.23 \% \pm 1.94 \%)$, and $6 \mathrm{mM} \mathrm{GSH}(29.67 \% \pm 3.83 \%)$.

Table 2. Structure of the four motile sperm subpopulations identified in frozen-thawed donkey sperm following cryopreservation with different reduced glutathione (GSH) concentrations.

\begin{tabular}{|c|c|c|c|c|c|c|c|c|}
\hline \multirow{2}{*}{ Parameter } & \multicolumn{2}{|c|}{ SP1 } & \multicolumn{2}{|c|}{ SP2 } & \multicolumn{2}{|c|}{ SP3 } & \multicolumn{2}{|c|}{ SP4 } \\
\hline & Mean \pm SEM & Range & Mean \pm SEM & Range & Mean \pm SEM & Range & Mean \pm SEM & Range \\
\hline $\operatorname{VCL}(\mu \mathrm{m} / \mathrm{s})$ & $265.51 \pm 0.81$ & $197.90-429.30$ & $69.32 \pm 0.35$ & $0.00-147.30$ & $198.68 \pm 0.35$ & $127.50-276.00$ & $134.67 \pm 0.32$ & $66.50-218.70$ \\
\hline $\operatorname{VSL}(\mu \mathrm{m} / \mathrm{s})$ & $115.39 \pm 0.54$ & $10.80-191.30$ & $15.79 \pm 0.13$ & $0.00-54.70$ & $83.56 \pm 0.30$ & $3.70-152.10$ & $49.42 \pm 0.22$ & $1.80-105.00$ \\
\hline $\operatorname{VAP}(\mu \mathrm{m} / \mathrm{s})$ & $131.57 \pm 0.40$ & $78.60-216.50$ & $33.31 \pm 0.19$ & $0.00-91.90$ & $99.91 \pm 0.22$ & $44.30-165.90$ & $69.05 \pm 0.17$ & $25.10-123.90$ \\
\hline LIN (\%) & $44.13 \pm 0.23$ & $3.90-75.30$ & $24.06 \pm 0.19$ & $0.00-92.30$ & $42.75 \pm 0.17$ & $1.50-95.60$ & $38.03 \pm 0.19$ & $1.20-100.00$ \\
\hline STR $(\%)$ & $87.42 \pm 0.27$ & $7.70-100.00$ & $48.01 \pm 0.29$ & $0.00-99.20$ & $83.59 \pm 0.23$ & $3.70-100.00$ & $71.71 \pm 0.25$ & $2.30-100.00$ \\
\hline WOB $(\%)$ & $50.09 \pm 0.18$ & $27.00-85.30$ & $48.88 \pm 0.17$ & $0.00-100.00$ & $50.80 \pm 0.13$ & $19.20-100.00$ & $52.32 \pm 0.14$ & $17.40-100.00$ \\
\hline $\mathrm{ALH}(\mu \mathrm{m})$ & $3.36 \pm 0.02$ & $1.50-6.40$ & $1.10 \pm 0.00$ & $0.00-2.80$ & $2.61 \pm 0.01$ & $0.80-4.00$ & $1.83 \pm 0.01$ & $0.40-3.50$ \\
\hline $\mathrm{BCF}(\mathrm{Hz})$ & $36.67 \pm 0.31$ & $0.00-73.50$ & $14.39 \pm 0.10$ & $0.00-52.40$ & $35.29 \pm 0.19$ & $0.00-72.10$ & $28.39 \pm 0.14$ & $0.00-70.80$ \\
\hline n (\%) & \multicolumn{2}{|c|}{1776 (9.97\%) } & \multicolumn{2}{|c|}{$5609(31.50 \%)$} & \multicolumn{2}{|c|}{$4339(24.36 \%)$} & \multicolumn{2}{|c|}{6085 (34.17) } \\
\hline
\end{tabular}

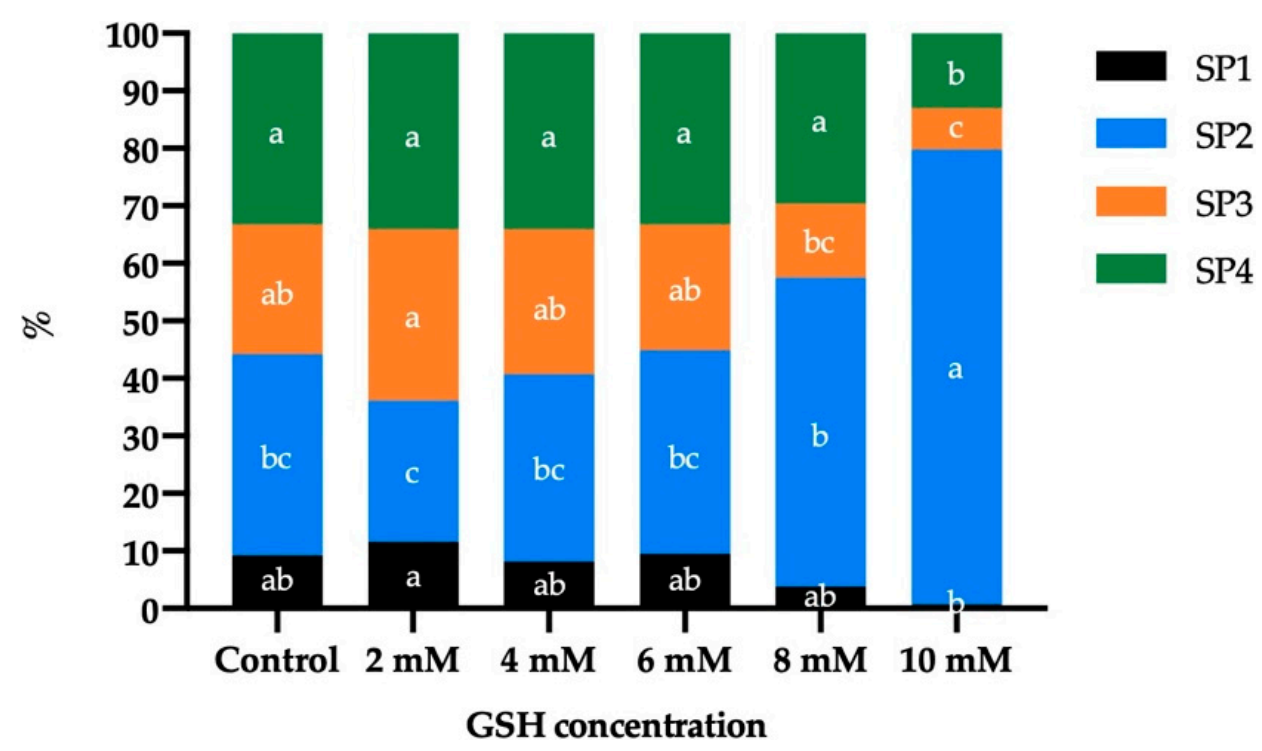

Figure 2. Distribution of the four motile sperm subpopulations (SP) identified in frozen-thawed donkey sperm following cryopreservation with different concentrations of reduced glutathione (GSH). (a-c) Different letters indicate significant differences $(p \leq 0.05)$ between the control and GSH treatments.

\subsection{Sperm Viability}

No significant differences in the viability of frozen-thawed donkey sperm (evaluated with eosin-nigrosin staining) between the different GSH concentrations and the control were found (Figure 3). 


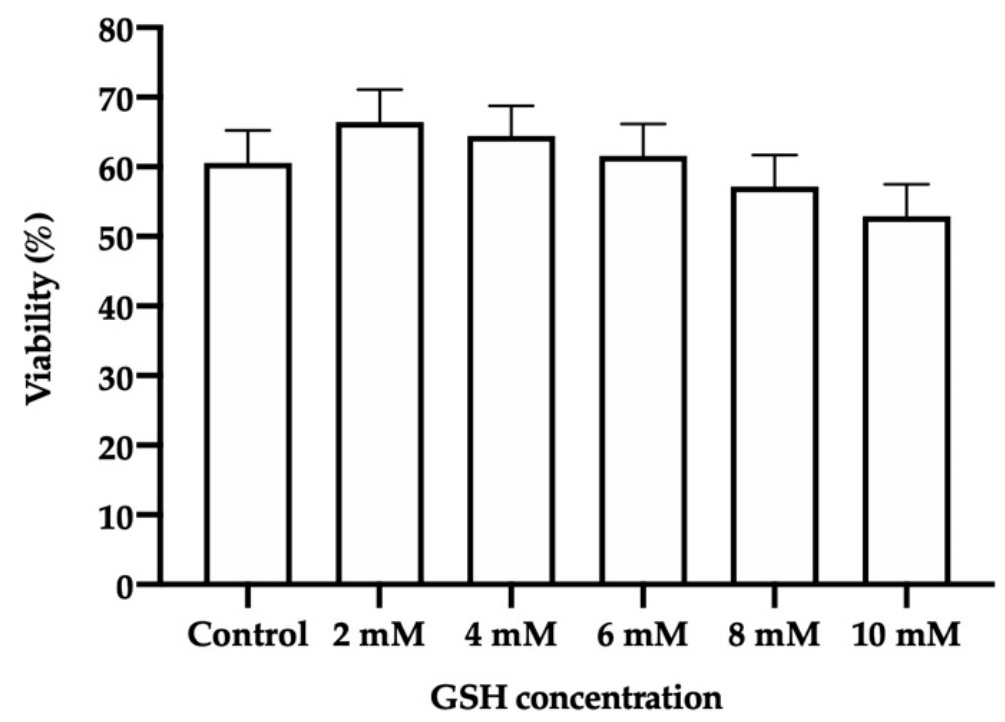

Figure 3. Mean \pm SEM of the viability of frozen-thawed donkey sperm following cryopreservation with different reduced glutathione (GSH) concentrations. No significant differences $(p \leq 0.05)$ between the control and GSH treatments were found.

\subsection{Sperm Quality}

\subsubsection{Sperm Membrane Integrity}

No significant differences in the percentage of frozen-thawed donkey sperm with intact plasma membrane (SYBR14 $\left.{ }^{+} / \mathrm{PI}^{-}\right)$were found between the control and the different GSH concentrations (Figure 4A).

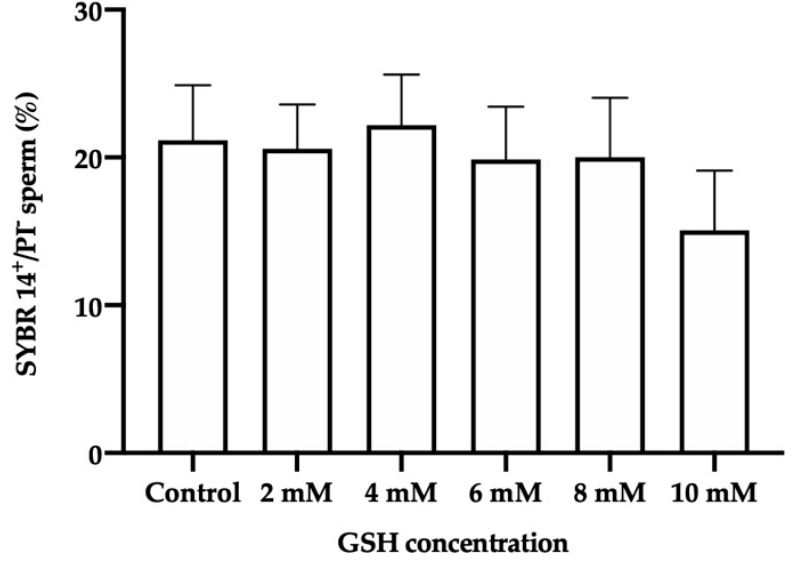

(A)

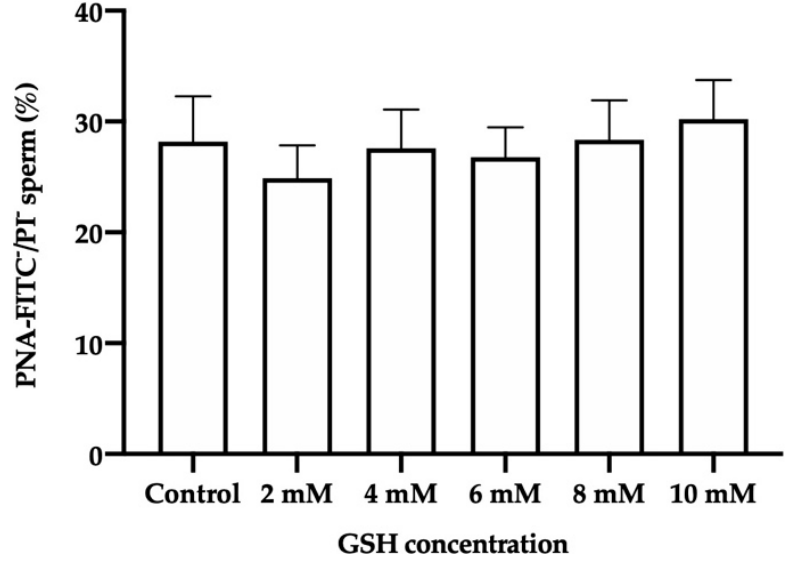

(B)

Figure 4. Mean \pm SEM of the percentages of sperm with an intact plasma membrane (SYBR14 ${ }^{+} / \mathrm{PI}^{-}$; (A)) and with an intact acrosome membrane (PNA-FITC ${ }^{-} / \mathrm{PI}^{-} ;(\mathbf{B})$ ) observed in frozen-thawed donkey sperm after cryopreservation with different GSH concentrations. No significant differences $(p \leq 0.05)$ between the control and GSH treatments were found.

\subsubsection{Acrosome Membrane Integrity}

Similarly, no significant differences in the percentage of frozen-thawed donkey sperm with an intact acrosome membrane (PNA-FITC ${ }^{-} / \mathrm{PI}^{-}$) were observed between the different GSH concentrations and the control (Figure 4B).

\subsubsection{Mitochondrial Membrane Potential (MPP)}

No significant differences in the percentage of frozen-thawed donkey sperm with high-MMP (JC-1 agg $_{\text {age }}$ were seen between the different GSH concentrations and the control (Figure 5A). Similarly, the GMFI of JC- $1_{\text {agg }}$ in the high-MMP sperm population did not differ from the control when GSH was added to the freezing medium (Figure 5B). 


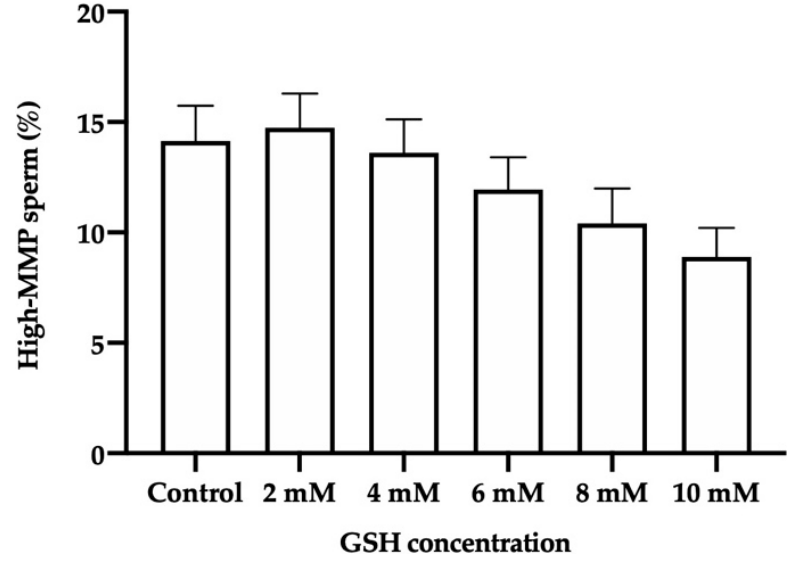

(A)

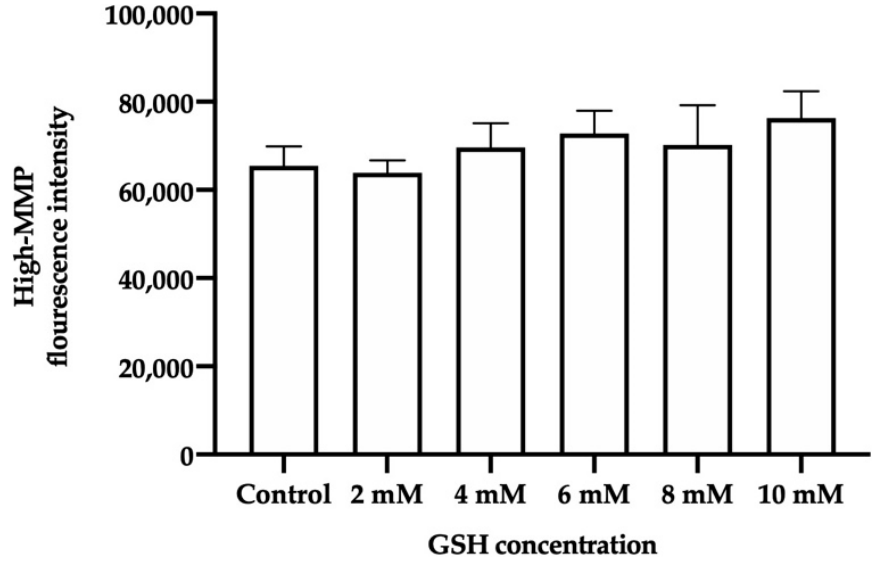

(B)

Figure 5. Mean \pm SEM of the percentage of spermatozoa with high mitochondrial membrane potential (high-MMP; higher proportion of JC- $1_{\text {agg }}$ than JC-1 $1_{\text {mon }}$ ) (A) and geometric mean fluorescence intensity of JC- $1_{\text {agg }}$ (GMFI, PE channel) in the sperm population with high-MMP (B) observed in frozen-thawed donkey sperm following cryopreservation with different GSH concentrations. No significant differences $(p \leq 0.05)$ between the control and GSH treatments were found.

\subsubsection{Intracellular Reactive Oxygen Species (ROS) Levels: $\mathrm{H}_{2} \mathrm{O}_{2}$ and $\mathrm{O}_{2}{ }^{-}$}

The GSH concentrations of $8 \mathrm{mM}$ and $10 \mathrm{mM}$ significantly $(p<0.05)$ decreased the percentage of frozen-thawed donkey sperm with high ROS levels ( $\mathrm{DCF}^{+} / \mathrm{PI}^{-}$) compared to the control $(9.33 \% \pm 1.91 \%$ and $9.36 \% \pm 1.81 \%$ vs. $19.72 \% \pm 3.13 \%$, respectively; Figure $6 \mathrm{~A})$. Exposure to any GSH concentration also reduced $(p<0.05)$ the GMFI of $\mathrm{DCF}^{+}$in the $\mathrm{DCF}^{+} / \mathrm{PI}^{-}$sperm population $(147,217.30 \pm 12,735.15$ in $2 \mathrm{mM} \mathrm{GSH}, 132,642.2 \pm 5966.27$ in $4 \mathrm{mM}$ GSH, 145,301.20 \pm 9617.71 in $6 \mathrm{mM} \mathrm{GSH}, 130,855.70 \pm 8405.67$ in $8 \mathrm{mM} \mathrm{GSH}$, and $133,857.40 \pm 9184.45$ in $10 \mathrm{mM}$ GSH) with respect to the control $(259,537.70 \pm 49,296.13$; Figure 6B).

On the other hand, no significant differences in either the percentage of frozen-thawed donkey sperm with high $\cdot \mathrm{O}_{2}^{-}$levels $\left(\mathrm{E}^{+} / \mathrm{YO}-\mathrm{PRO}-1^{-}\right)$or the GMFI of $\mathrm{E}^{+}$in the $\mathrm{E}^{+} / \mathrm{YO}-$ PRO- $1^{-}$sperm population were observed between the different GSH concentrations and the control (Figure 6C,D).

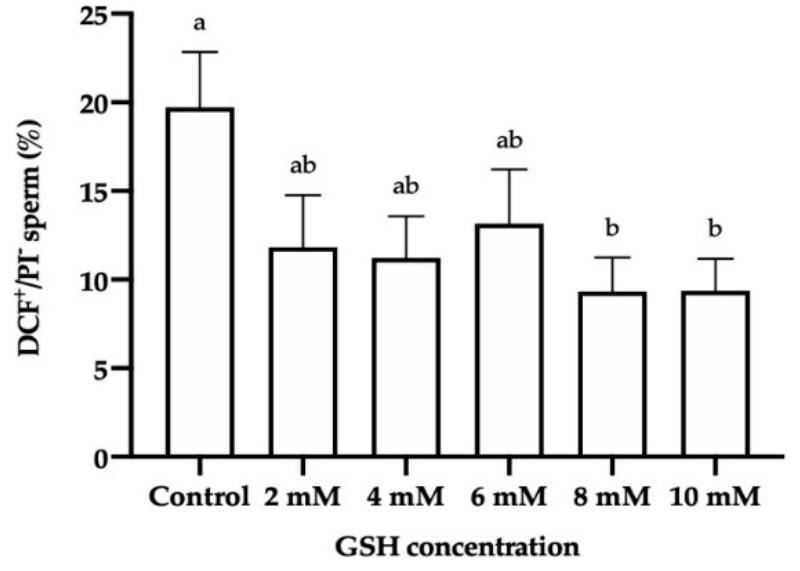

(A)

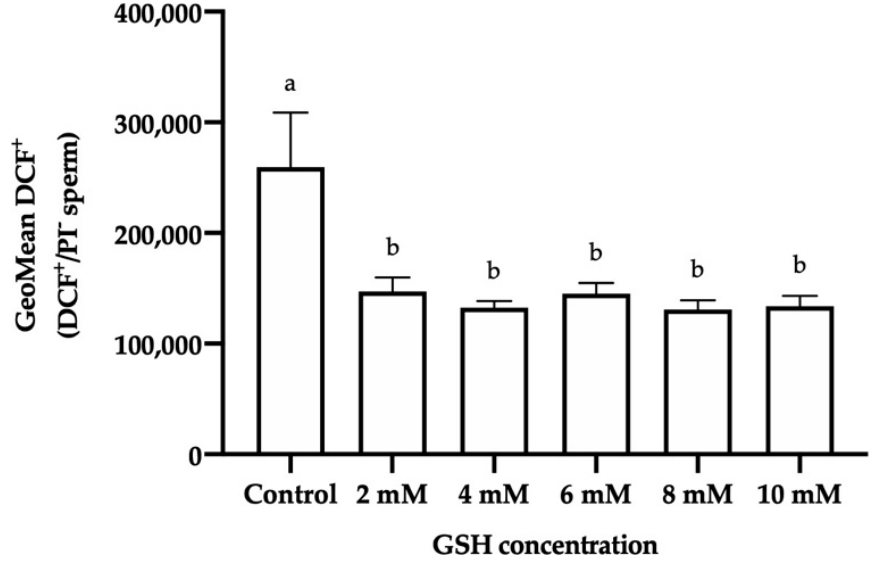

(B)

Figure 6. Cont. 


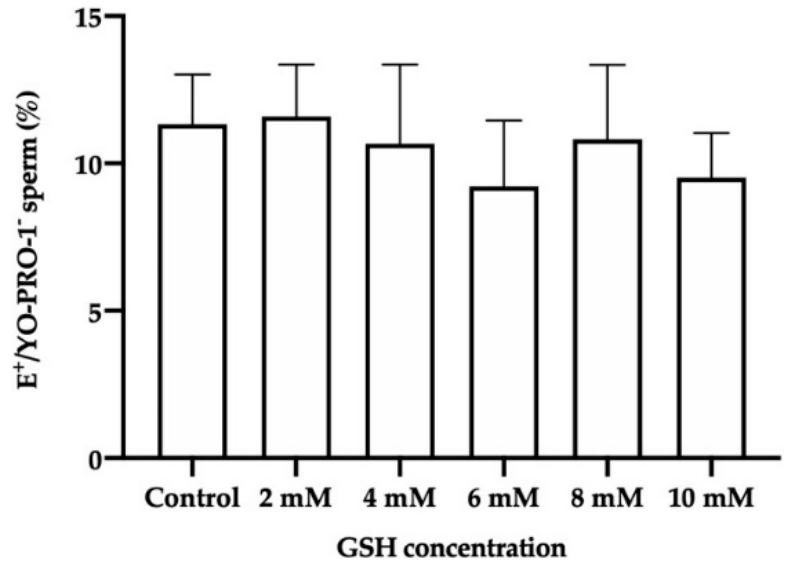

(C)

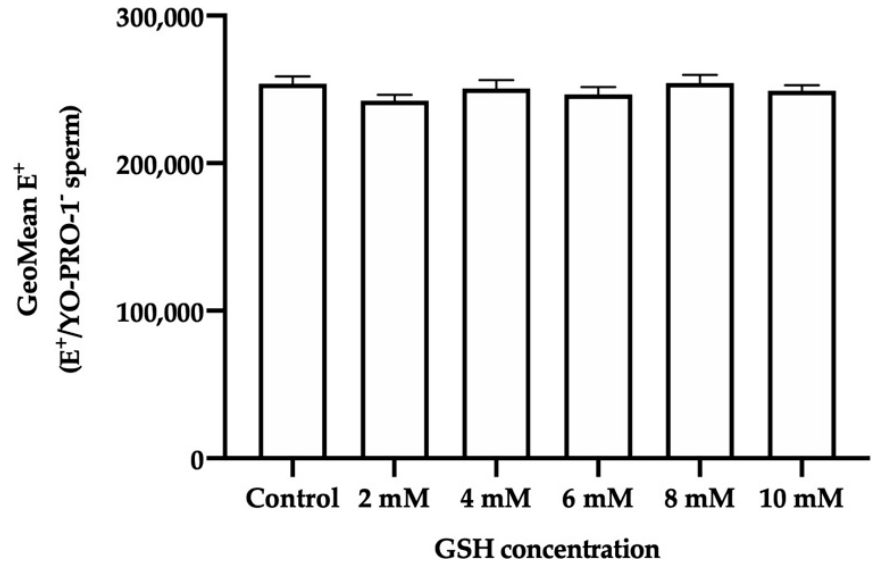

(D)

Figure 6. Mean \pm SEM of the percentage of viable sperm with high overall ROS levels $\left(\mathrm{DCF}^{+} / \mathrm{PI}^{-}\right.$, $\left.(\mathbf{A})\right)$, geometric mean fluorescence intensity of $\mathrm{DCF}^{+}$(GMFI, FITC channel) in the $\mathrm{DCF}^{+} / \mathrm{PI}^{-}$sperm population (B), percentage of viable spermatozoa with high $\cdot \mathrm{O}_{2}{ }^{-}$levels $\left(\mathrm{E}^{+} / \mathrm{YO}-\mathrm{PRO}-1^{-},(\mathrm{C})\right)$, and geometric mean fluorescence intensity of $\mathrm{E}^{+}(\mathrm{GMFI}$, channel $\mathrm{PE})$ in the $\mathrm{E}^{+} / \mathrm{YO}-\mathrm{PRO}-1^{-}$sperm population (D) observed in frozen-thawed donkey sperm following cryopreservation with different reduced glutathione (GSH) concentrations. (a,b) Different letters indicate significant differences $(p \leq 0.05)$ between the control and GSH concentrations in (A,B). No significant differences $(p \leq 0.05)$ between the control and GSH treatments in $(\mathbf{C}, \mathbf{D})$ were found.

\section{Discussion}

The combination of the cellular component (sperm) produced by the germinal epithelium of the testes and the liquid component (SP) generated by the epididymis and the accessory sex glands $[63,64]$ causes semen to become a complex redox system due to the antioxidant action exerted mostly by SP and, to a lesser extent, by sperm, as well as by the pro-oxidant action of sperm through ROS production [65]. This last action is more important during sperm cryopreservation in equids, because sperm cells lose the antioxidant support of SP before freezing. While intracellular GSH levels in horse sperm have been quantified [66], it is not clear whether this produced amount is high enough for sperm to have the ability to scavenge the oxidative stress generated by ROS and thus maintain redox balance without the antioxidant support of SP. In the case of donkeys, it has recently been shown that sperm are capable of tolerating high ROS concentrations $\left(\mathrm{H}_{2} \mathrm{O}_{2}\right)$ and that in the presence of PMN, SP plays a decisive role in the regulation of the ROS produced during NETosis [36]. In this scenario, the addition of exogenous GSH could compensate in a certain way for the antioxidant component that sperm lose when cryopreserved.

The first hypothesis of this study envisaged that adding GSH to the freezing medium would increase the ability of donkey sperm to withstand cryopreservation. However, our results indicate that supplementation of the freezing medium with GSH at a concentration as high as $10 \mathrm{mM}$ does not affect the viability, plasma and acrosome membrane integrity, and MMP of post-thaw sperm. However, sperm motility was reduced almost to zero. This surprising finding in the donkey provides us with valuable information to understand the reproductive strategy in this species, since the tolerance to GSH observed herein was much higher than that reported in horses [43], pigs [41], sheep [42], cattle [45], and dogs [44]. In effect, in those species, adding high concentrations of GSH to the freezing medium results in a significant decrease in all the aforementioned parameters of post-thaw sperm; in fact, in some cases, these high concentrations have even been reported to be cytotoxic [43].

Regarding the motility of frozen-thawed donkey sperm, we observed a significant effect of high GSH concentrations on TM and PM, which decreased in the presence of $8 \mathrm{mM}$ $(29.36 \% \pm 6.88 \%$ and $9.76 \% \pm 3.95 \%$, respectively $)$ and $10 \mathrm{mM} \mathrm{GSH}(7.85 \% \pm 3.10 \%$ and $1.65 \% \pm 0.96 \%$, respectively) with respect to the control $(62.56 \% \pm 4.81 \%$ and $34.05 \% \pm 4.61 \%$, respectively). Interestingly, frozen-thawed donkey sperm were found to be more tolerant to exogenous GSH supplementation than their horse counterparts, as TM and PM in the latter 
are known to be reduced in the presence of $5 \mathrm{mM}$ and $2.5 \mathrm{mM} \mathrm{GSH}$, respectively. Similarly, VSL, LIN, STR, and BCF values were significantly reduced at $8 \mathrm{mM}$ and $10 \mathrm{mM} \mathrm{GSH}$, whereas the other kinematic parameters (VCL, VAP, WOB, and ALH) were affected in the presence of $10 \mathrm{mM}$ GSH. In addition, in horse sperm, LIN, STR, and BCF are decreased in the presence of a GSH concentration $\geq 2.5 \mathrm{mM}$; furthermore, VSL and ALH are decreased at $\geq 5 \mathrm{mM}$ GSH, and VCL and VAP are decreased at $\geq 7.5 \mathrm{mM} \mathrm{GSH} \mathrm{[43].} \mathrm{Moreover,} \mathrm{four}$ separate subpopulations were herein identified in frozen-thawed donkey sperm, which is in agreement with previous research in this species $[27,50,67]$. We found that the treatment containing $10 \mathrm{mM}$ GSH significantly increased the proportion of sperm belonging to SP2 (the slowest and least progressive subpopulation), reduced those of sperm belonging to SP3 and SP4 (the subpopulations with intermediate kinematic parameters), and did not affect that of SP1 (the fastest and most progressive subpopulation) with respect to the control. Remarkably, $2 \mathrm{mM}, 4 \mathrm{mM}$, and $6 \mathrm{mM}$ GSH were found not to modify the structure of the frozen-thawed motile sperm subpopulations compared to the control. The analysis of sperm subpopulations once again highlighted the cryotolerance of frozen-thawed donkey sperm as, while the presence of $2 \mathrm{mM}$ GSH is known to modify the structure of those subpopulations in pigs, increasing the fastest subpopulation and decreasing the slowest one [68], no changes were observed herein for concentrations $\leq 6 \mathrm{mM} \mathrm{GSH}$.

While sperm viability and integrities of plasma and acrosome membranes were not affected by the presence of high GSH concentrations, no treatment, even the ones containing low concentrations of this antioxidant, improved these sperm parameters post-thaw. This is contrary to what was found by Kumar et al. [16] in frozen-thawed sperm from exotic donkeys (Poitou breed, Martina Franca), where there was a significant increase in motility, viability and plasma membrane integrity when the freezing medium was supplemented with $2.5 \mathrm{mM}$. Our results, however, agree with the aforementioned study in the percentage of sperm with an intact acrosome membrane, since no differences in this parameter were observed in our study or in that of Kumar et al. [16], even when using two different techniques (flow cytometry vs. Giemsa stain + microscopy). Moreover, comparing our results with those found in other species may provide some clues, despite the fact that inconsistent data are seen in the literature. In cattle, Gangwar et al. [45] observed that adding $0.5 \mathrm{mM}$ GSH to the freezing medium increased the viability, plasma and acrosome membrane integrity, and MMP of frozen-thawed sperm. In horses, Oliveira et al. [39] reported that a higher concentration of GSH $(2.5 \mathrm{mM})$ was required to observe an improvement in the percentage of post-thaw sperm with an intact plasma membrane, despite the fact that acrosome integrity was similar to the control. In pigs, Estrada et al. [69] supplemented the freezing medium with $2 \mathrm{mM}$ GSH and observed an increase in the percentages of viable and acrosome-intact sperm, and in fertilizing ability. On the contrary, Silva et al. [42] did not find any improvement in the quality (plasma and acrosome membrane integrity, and MMP) of frozen-thawed sheep sperm with $2 \mathrm{mM} \mathrm{GSH}$ in relation to the control, which was in agreement with our observations in the current study.

As previously mentioned, whereas TM and PM were found to decrease when $8 \mathrm{mM}$ and $10 \mathrm{mM}$ GSH were added to the freezing medium, viability, plasma and acrosome membrane integrity, and MMP did not differ from the control. Moreover, we observed that the percentage of viable sperm with high intracellular ROS levels was significantly lower in the treatments containing $8 \mathrm{mM}$ and $10 \mathrm{mM} \mathrm{GSH}$ than in the control. These observations are in relative or slight agreement with our second hypothesis, which suggested that motility, viability, plasma and acrosome membrane integrity, MMP, and intracellular ROS levels of post-thaw sperm would be affected by the addition of GSH to the freezing medium. ROS production is known to alter the function and structure of sperm membranes [70], causing a detrimental effect on sperm motility and membrane integrity [22]. Our results indicate that the detrimental effects of ROS could be counteracted by the presence of GSH. However, the other parameters of sperm functionality did not improve with the presence of GSH. In fact, the results showed that GSH is effective in scavenging ROS up to $8 \mathrm{mM}$, and could have an effect on sperm motility. Further studies are needed to address whether fertility is 
also compromised or if other antioxidants are able to improve the functionality and fertility of donkey sperm. As the post-translational modification of protein thiols is the most likely mechanism to maintain redox balance [41,71], one could speculate that supplementing the freezing medium with exogenous GSH could reverse the oxidative stress generated during the freezing and thawing of donkey sperm. This could maintain the integrity of plasma and acrosome membranes.

On the other hand, it is important to highlight that GSH supplementation did not affect the production of intracellular $\mathrm{O}_{2}^{-}$levels during cryopreservation. Physiologically, $\mathrm{O}_{2}{ }^{-}$is scavenged by superoxide dismutase (SOD) [72], another antioxidant enzyme present in donkey SP, rather than by the glutathione complex enzymes (GSR and GPX). Freezethawing reduces SOD activity in response to an increase in $\mathrm{O}_{2}{ }^{-}$production [65]; this enzyme converts $\mathrm{O}_{2}{ }^{-}$into $\mathrm{H}_{2} \mathrm{O}_{2}$ by dismutation [73]. This leads one to posit that if there was high $\mathrm{O}_{2}{ }^{-}$production in the long run, there would be a greater amount of $\mathrm{H}_{2} \mathrm{O}_{2}$. This excess of $\mathrm{H}_{2} \mathrm{O}_{2}$ could be scavenged by exogenous GSH and thus reduce the percentage of sperm with high $\mathrm{H}_{2} \mathrm{O}_{2}$ levels, as reported herein.

Another important implication of our results is related to what happens in the jenny's endometrium when $\mathrm{AI}$ is performed with frozen-thawed semen. In this scenario, donkey sperm are exposed to an oxidative environment in the uterus, which results from the production of ROS by PMN during the NETosis triggered by the presence of sperm [21]. Based on our results, GSH concentrations were not able to scavenge intracellular sperm ROS levels. Therefore, it seems reasonable to suggest that exogenous GSH supplementation between $2 \mathrm{mM}$ and $6 \mathrm{mM}$ could be a strategy against oxidative stress in this species after cryopreservation. This could be especially relevant after freeze-thawing if one bears in mind that $\mathrm{SP}$, which is the main antioxidant source in semen, is removed before cryopreservation. However, one aspect that must be taken into account is that the degree of reduction in intracellular ROS levels observed at high GSH concentrations ( $8 \mathrm{mM}$ and $10 \mathrm{mM})$ was not sufficient to positively affect sperm motility; in fact, it reduced sperm motility. This would not be in agreement with most observations in other mammalian species that indicate that sperm sensitivity to oxidative stress and cryogenic damage results in a reduction in motility after freeze-thawing $[45,74,75]$. In effect, we observed that, although high concentrations of GSH regulated the intracellular ROS levels, motility decreased. This opposite relationship advises that the impact of ROS on the other functional parameters in donkey sperm differs from other species.

\section{Conclusions}

According to the results obtained, frozen-thawed donkey sperm were found, on the one hand, to have a surprising capacity to tolerate high GSH concentrations compared to other species, maintaining viability, plasma membrane and acrosome integrity, and MMP. On the other hand, supplementation of the freezing medium with GSH appears to be necessary to control intracellular ROS levels, mainly $\mathrm{H}_{2} \mathrm{O}_{2}$, produced during freeze-thawing as well as post-AI, and may improve reproductive performance in the jenny. However, the highest GSH concentrations ( $8 \mathrm{mM}$ and $10 \mathrm{mM}$ ) affected sperm motility, which suggests that how donkey sperm handle ROS generation differs from other species. Therefore, conducting in vivo studies is much warranted to complement the results obtained in this work.

Author Contributions: Conceptualization, M.Y. and J.M.; methodology, I.Y.-O., J.C., A.D.-B. and A.C.; validation, M.Y. and J.M.; formal analysis, I.Y.-O.; investigation, I.Y.-O. and J.C.; resources, M.Y. and J.M.; data curation, I.Y.-O.; writing—original draft preparation, I.Y.-O.; writing-review and editing, A.D.-B., M.Y. and J.M.; supervision M.Y. and J.M.; project administration, M.Y. and J.M.; funding acquisition, M.Y. and J.M. All authors have read and agreed to the published version of the manuscript.

Funding: I.Y.-O. was funded by the Secretary of Higher Education, Science, Technology and Innovation (SENESCYT), Ecuador (Scheme: Programa de Becas Internacionales de Posgrado 2019; Grant: CZ02-000507-2019). J.C. was funded by the "Demetra" project of the Department of Excel- 
lence Postdoctoral fellowship, University of Teramo, Italy (Scheme: Assegno di Recerca 2021). The authors also acknowledge the support from the Ministry of Science and Innovation, Spain (Grant: AGL2017-88329-R) and the Regional Government of Catalonia (2017-SGR-1229).

Institutional Review Board Statement: The Ethics Committee of the Autonomous University of Barcelona (CEEAH) considered that the study is exempted of clearance.

Informed Consent Statement: The informed consent was obtained from owner of Catalonian jackasses in this study.

Data Availability Statement: All data is contained within the article.

Acknowledgments: The authors would like to thank Jordi Ribas-Maynou from the Biotechnology of Animal and Human Reproduction (TechnoSperm), University of Girona, Spain, for his support in handling the flow cytometer.

Conflicts of Interest: The authors declare no conflict of interest.

\section{References}

1. Sherman, J.K. Low temperature research on spermatozoa and eggs. Cryobiology 1964, 1, 103-129. [CrossRef]

2. Loomis, P.R. Advanced methods for handling and preparation of stallion semen. Vet. Clin. N. Am. Equine Pract. 2006, 22, 663-676. [CrossRef] [PubMed]

3. Fickel, J.; Wagener, A.; Ludwig, A. Semen cryopreservation and the conservation of endangered species. Eur. J. Wildl. Res. 2007, 53, 81-89. [CrossRef]

4. Camillo, F.; Rota, A.; Biagini, L.; Tesi, M.; Fanelli, D.; Panzani, D. The current situation and trend of donkey industry in Europe. J. Equine Vet. Sci. 2018, 65, 44-49. [CrossRef]

5. Aranguren-Méndez, J.; Jordana, J.; Gomez, M. Genetic diversity in Spanish donkey breeds using microsatellite DNA markers. Genet. Sel. Evol. 2001, 33,1-10. [CrossRef]

6. Trimeche, A.; Renard, P.; Tainturier, D. A procedure for Poitou jackass sperm cryopreservation. Theriogenology 1998, 50, 793-806. [CrossRef]

7. Vidament, M.; Vincent, P.; Martin, F.X.; Magistrini, M.; Blesbois, E. Differences in ability of jennies and mares to conceive with cooled and frozen semen containing glycerol or not. Anim. Reprod. Sci. 2009, 112, 22-35. [CrossRef] [PubMed]

8. Oliveira, J.V.; Papa, F.O.; Melo-Oña, C.M.; Monteiro, G.A.; Puoli-Filho, J.N.P.; Alvarenga, M.A. New procedures to freeze donkey semen and its influence on mares and jennies fertility. J. Equine Vet. Sci. 2012, 32, 503-504. [CrossRef]

9. Rota, A.; Panzani, D.; Sabatini, C.; Camillo, F. Donkey jack (Equus asinus) semen cryopreservation: Studies of seminal parameters, post breeding inflammatory response, and fertility in donkey jennies. Theriogenology 2012, 78, 1846-1854. [CrossRef]

10. Pukazhenthi, B.S.; Johnson, A.; Guthrie, H.D.; Songsasen, N.; Padilla, L.R.; Wolfe, B.A.; Coutinho da Silva, M.; Alvarenga, M.A.; Wildt, D.E. Improved sperm cryosurvival in diluents containing amides versus glycerol in the Przewalski's horse (Equus ferus przewalskii). Cryobiology 2014, 68, 205-214. [CrossRef]

11. Ortiz, I.; Dorado, J.; Morrell, J.M.; Crespo, F.; Gosálvez, J.; Gálvez, M.J.; Acha, D.; Hidalgo, M. Effect of single-layer centrifugation or washing on frozen-thawed donkey semen quality: Do they have the same effect regardless of the quality of the sample? Theriogenology 2015, 84, 294-300. [CrossRef]

12. Acha, D.; Hidalgo, M.; Ortiz, I.; Gálvez, M.J.; Carrasco, J.J.; Gómez-Arrones, V.; Dorado, J. Freezability of Andalusian donkey (Equus asinus) spermatozoa: Effect of extenders and permeating cryoprotectants. Reprod. Fertil. Dev. 2016, 28, 1990-1998. [CrossRef] [PubMed]

13. Oliveira, J.V.; Oliveira, P.V.L.F.; Melo-Oña, C.M.; Guasti, P.N.; Monteiro, G.A.; Sancler da Silva, Y.F.R.; Papa, P.M.; Alvarenga, M.A.; Dell'Aqua, J.A.; Papa, F.O. Strategies to improve the fertility of fresh and frozen donkey semen. Theriogenology 2016, 85, 1267-1273. [CrossRef] [PubMed]

14. Bottrel, M.; Acha, D.; Ortiz, I.; Hidalgo, M.; Gósalvez, J.; Camisão, J.; Dorado, J. Cryoprotective effect of glutamine, taurine, and proline on post-thaw semen quality and DNA integrity of donkey spermatozoa. Anim. Reprod. Sci. 2018, 189, 128-135. [CrossRef]

15. Zhang, H.; Ye, H.; Shao, Y.; Wu, S.; Yu, J.; Ji, C.; Wang, S.; Zeng, S. The effects of egg yolk concentration and particle size on donkey semen preservation. J. Equine Vet. Sci. 2018, 65, 19-24. [CrossRef]

16. Kumar, P.; Kumar, R.; Mehta, J.S.; Chaudhary, A.K.; Ravi, S.K.; Chandra Mehta, S.; Ansari, M.M.; Legha, R.A.; Tripathi, B.N.; Talluri, T.R. Ameliorative effect of ascorbic acid and glutathione in combating the cryoinjuries during cryopreservation of exotic jack semen. J. Equine Vet. Sci. 2019, 81, 102796. [CrossRef]

17. Yu, X.; He, S.; Wang, L.; Kang, M.; Zhu, Y.; Wang, S.; Sun, X. Effects of Vitamin C and Vitamin E on cryopreservation of Guanzhong donkey semen. Pak. J. Zool. 2019, 51, 1777-1781. [CrossRef]

18. Li, N.; Yu, J.; Yang, F.; Shao, Y.; Wu, S.; Liu, B.; Li, M.; Wang, T.; Li, J.; Zeng, S. L-proline: An effective agent for frozen and post-thawed donkey semen storage. J. Equine Vet. Sci. 2021, 101, 103393. [CrossRef] [PubMed] 
19. Canisso, I.F.; Carvalho, G.R.; Davis Morel, M.; Ker, P.G.; Rodrigues, A.L.; Silva, E.C.; Coutinho Da Silva, M.A. Seminal parameters and field fertility of cryopreserved donkey jack semen after insemination of horse mares. Equine Vet. J. 2011, 43, 179-183. [CrossRef]

20. Vilés, K.; Rabanal, R.; Rodríguez-Prado, M.; Miró, J. Effect of ketoprofen treatment on the uterine inflammatory response after AI of jennies with frozen semen. Theriogenology 2013, 79, 1019-1026. [CrossRef] [PubMed]

21. Miró, J.; Papas, M. Post-Artificial Insemination endometrial inflammation and its control in donkeys. J. Equine Vet. Sci. 2018, 65, 38-43. [CrossRef]

22. Yeste, M. Sperm cryopreservation update: Cryodamage, markers, and factors affecting the sperm freezability in pigs. Theriogenology 2016, 85, 47-64. [CrossRef] [PubMed]

23. Aitken, R.J.; De Iuliis, G.N.; Drevet, J.R. Role of oxidative stress in the etiology of male infertility and the potential therapeutic value of antioxidants. In Oxidants, Antioxidants, and Impact of the Oxidative Status in Male Reproduction; Elsevier: London, UK, 2018; pp. 91-100.

24. Peña, F.J.; O’Flaherty, C.; Ortiz Rodríguez, J.M.; Martín Cano, F.E.; Gaitskell-Phillips, G.L.; Gil, M.C.; Ortega Ferrusola, C. Redox regulation and oxidative stress: The particular case of the stallion spermatozoa. Antioxidants 2019, 8, 567. [CrossRef]

25. Kim, J.G.; Parthasarathy, S. Oxidation and the spermatozoa. Semin. Reprod. Endocrinol. 1998, 16, 235-239. [CrossRef]

26. Papas, M.; Arroyo, L.; Bassols, A.; Catalán, J.; Bonilla-Correal, S.; Gacem, S.; Yeste, M.; Miró, J. Activities of antioxidant seminal plasma enzymes (SOD, CAT, GPX and GSR) are higher in jackasses than in stallions and are correlated with sperm motility in jackasses. Theriogenology 2019, 140, 180-187. [CrossRef] [PubMed]

27. Papas, M.; Catalán, J.; Recuero, S.; Morrell, J.M.; Yeste, M.; Miró, J. Single layer centrifugation improves the quality of fresh donkey semen and modifies the sperm ability to interact with polymorphonuclear neutrophils. Animals 2020, 10, 2128. [CrossRef] [PubMed]

28. Dutta, S.; Majzoub, A.; Agarwal, A. Oxidative stress and sperm function: A systematic review on evaluation and management. Arab J. Urol. 2019, 17, 87-97. [CrossRef]

29. Yeste, M.; Estrada, E.; Casas, I.; Bonet, S.; Rodríguez-Gil, J.E. Good and bad freezability boar ejaculates differ in the integrity of nucleoprotein structure after freeze-thawing but not in ROS levels. Theriogenology 2013, 79, 929-939. [CrossRef] [PubMed]

30. Kotilainen, T.; Huhtinen, M.; Katila, T. Sperm-induced leukocytosis in the equine uterus. Theriogenology 1994, 41, 629-636. [CrossRef]

31. Troedsson, M.H.T.; Loset, K.; Alghamdi, A.M.; Dahms, B.; Crabo, B.G. Interaction between equine semen and the endometrium: The inflammatory response to semen. Anim. Reprod. Sci. 2001, 68, 273-278. [CrossRef]

32. Rodriguez-Martinez, H.; Saravia, F.; Wallgren, M.; Martinez, E.A.; Sanz, L.; Roca, J.; Vazquez, J.M.; Calvete, J.J. Spermadhesin PSP-I/PSP-II heterodimer induces migration of polymorphonuclear neutrophils into the uterine cavity of the sow. J. Reprod. Immunol. 2010, 84, 57-65. [CrossRef]

33. Zambrano, F.; Carrau, T.; Gärtner, U.; Seipp, A.; Taubert, A.; Felmer, R.; Sanchez, R.; Hermosilla, C. Leukocytes coincubated with human sperm trigger classic neutrophil extracellular traps formation, reducing sperm motility. Fertil. Steril. 2016, 106, 1053-1060. [CrossRef] [PubMed]

34. Miró, J.; Marín, H.; Catalán, J.; Papas, M.; Gacem, S.; Yeste, M. Seminal plasma, sperm concentration, and sperm-PMN interaction in the donkey: An in vitro model to study endometrial inflammation at post-insemination. Int. J. Mol. Sci. 2020, $21,3478$. [CrossRef]

35. Baumber, J.; Vo, A.; Sabeur, K.; Ball, B.A. Generation of reactive oxygen species by equine neutrophils and their effect on motility of equine spermatozoa. Theriogenology 2002, 57, 1025-1033. [CrossRef]

36. Yánez-Ortiz, I.; Catalán, J.; Mateo-Otero, Y.; Dordas-Perpinyà, M.; Gacem, S.; Yeste, N.; Bassols, A.; Yeste, M.; Miró, J. Extracellular reactive oxygen species (ROS) production in fresh donkey sperm exposed to reductive stress, oxidative stress and NETosis. Antioxidants 2021, 10, 1367. [CrossRef]

37. Gadea, J.; Molla, M.; Selles, E.; Marco, M.A.; Garcia-Vazquez, F.A.; Gardon, J.C. Reduced glutathione content in human sperm is decreased after cryopreservation: Effect of the addition of reduced glutathione to the freezing and thawing extenders. Cryobiology 2011, 62, 40-46. [CrossRef] [PubMed]

38. Câmara, D.R.; Mello-Pinto, M.M.C.; Pinto, L.C.; Brasil, O.O.; Nunes, J.F.; Guerra, M.M.P. Effects of reduced glutathione and catalase on the kinematics and membrane functionality of sperm during liquid storage of ram semen. Small Rumin. Res. 2011, 100, 44-49. [CrossRef]

39. Ansari, M.S.; Rakha, B.A.; Andrabi, S.M.H.; Ullah, N.; Iqbal, R.; Holt, W.V.; Akhter, S. Glutathione-supplemented tris-citric acid extender improves the post-thaw quality and in vivo fertility of buffalo (Bubalus bubalis) bull spermatozoa. Reprod. Biol. 2012, 12, 271-276. [CrossRef]

40. Oliveira, R.A.; Piersanti, R.L.; Wolf, C.A.; Viu, M.A.O.; Gambarini, M.L. Glutathione for the freezing of cooled equine semen, using different protocols. Anim. Reprod. 2018, 11, 104-109.

41. Ahmad, E.; Naseer, Z.; Aksoy, M. Glutathione supplementation in semen extender improves rabbit sperm attributes during refrigeration. World Rabbit Sci. 2021, 29, 81. [CrossRef]

42. Gadea, J.; García-Vazquez, F.; Matás, C.; Gardón, J.C.; Cánovas, S.; Gumbao, D. Cooling and freezing of boar spermatozoa: Supplementation of the freezing media with reduced glutathione preserves sperm function. J. Androl. 2005, 26, 396-404. [CrossRef] [PubMed] 
43. Silva, S.V.; Soares, A.T.; Batista, A.M.; Almeida, F.C.; Nunes, J.F.; Peixoto, C.A.; Guerra, M.M.P. In vitro and in vivo evaluation of ram sperm frozen in tris egg-yolk and supplemented with superoxide dismutase and reduced glutathione. Reprod. Domest. Anim. 2011, 46, 874-881. [CrossRef]

44. Oliveira, R.A.; Wolf, C.A.; Viu, M.A.O.; Gambarini, M.L. Addition of glutathione to an extender for frozen equine semen. J. Equine Vet. Sci. 2013, 33, 1148-1152. [CrossRef]

45. Ogata, K.; Sasaki, A.; Kato, Y.; Takeda, A.; Wakabayashi, M.; Sarentonglaga, B.; Yamaguchi, M.; Hara, A.; Fukumori, R.; Nagao, Y. Glutathione supplementation to semen extender improves the quality of frozen-thawed canine spermatozoa for transcervical insemination. J. Reprod. Dev. 2015, 61, 116-122. [CrossRef] [PubMed]

46. Gangwar, C.; Saxena, A.; Patel, A.; Singh, S.P.; Yadav, S.; Kumar, R.; Singh, V. Effect of reduced glutathione supplementation on cryopreservation induced sperm cryoinjuries in Murrah bull semen. Anim. Reprod. Sci. 2018, 192, 171-178. [CrossRef]

47. Luberda, Z. The role of glutathione in mammalian gametes. Reprod. Biol. 2005, 5, 5-17.

48. Irvine, D.S. Glutathione as a treatment for male infertility. Rev. Reprod. 1996, 1, 6-12. [CrossRef] [PubMed]

49. Yeste, M.; Flores, E.; Estrada, E.; Bonet, S.; Rigau, T.; Rodríguez-Gil, J.E. Reduced glutathione and procaine hydrochloride protect the nucleoprotein structure of boar spermatozoa during freeze-thawing by stabilising disulfide bonds. Reprod. Fertil. Dev. 2013, 25, 1036-1050. [CrossRef]

50. Miró, J.; Lobo, V.; Quintero-Moreno, A.; Medrano, A.; Peña, A.; Rigau, T. Sperm motility patterns and metabolism in Catalonian donkey semen. Theriogenology 2005, 63, 1706-1716. [CrossRef]

51. Canisso, I.F.; Panzani, D.; Miró, J.; Ellerbrock, R.E. Key aspects of donkey and mule reproduction. Vet. Clin. N. Am. Equine Pract. 2019, 35, 607-642. [CrossRef]

52. Gacem, S.; Papas, M.; Catalan, J.; Miró, J. Examination of jackass (Equus asinus) accessory sex glands by B-mode ultrasound and of testicular artery blood flow by colour pulsed-wave Doppler ultrasound: Correlations with semen production. Reprod. Domest. Anim. 2020, 55, 181-188. [CrossRef]

53. Kenney, M.R. Minimal contamination techniques for breeding mares: Techniques and priliminary findings. Proc. Am. Assoc. Equine Pract. 1975, 327-336.

54. Gacem, S.; Catalán, J.; Valverde, A.; Soler, C.; Miró, J. Optimization of CASA-mot analysis of donkey sperm: Optimum frame rate and values of kinematic variables for different counting chamber and fields. Animals 2020, 10, 1993. [CrossRef]

55. Bamba, K. Evaluation of acrosomal integrity of boar spermatozoa by bright field microscopy using an eosin-nigrosin stain. Theriogenology 1988, 29, 1245-1251. [CrossRef]

56. Lee, J.A.; Spidlen, J.; Boyce, K.; Cai, J.; Crosbie, N.; Dalphin, M.; Furlong, J.; Gasparetto, M.; Goldberg, M.; Goralczyk, E.M.; et al. MIFlowCyt: The minimum information about a flow cytometry experiment. Cytometry 2008, 73, 926-930. [CrossRef] [PubMed]

57. Garner, D.L.; Johnson, L.A. Viability assessment of mammalian sperm using SYBR-14 and propidium iodide. Biol. Reprod. 1995, 53, 276-284. [CrossRef] [PubMed]

58. Rathi, R.; Colenbrander, B.; Bevers, M.M.; Gadella, B.M. Evaluation of in vitro capacitation of stallion spermatozoa. Biol. Reprod. 2001, 65, 462-470. [CrossRef] [PubMed]

59. Ortega-Ferrusola, C.; Sotillo-Galán, Y.; Varela-Fernández, E.; Gallardo-Bolaños, J.M.; Muriel, A.; González-Fernández, L.; Tapia, J.A.; Peña, F.J. Detection of "apoptosis-like" changes during the cryopreservation process in equine sperm. J. Androl. 2008, 29, 213-221. [CrossRef]

60. Morrell, J.M.; Winblad, C.; Georgakas, A.; Stuhtmann, G.; Humblot, P.; Johannisson, A. Reactive oxygen species in stallion semen can be affected by season and colloid centrifugation. Anim. Reprod. Sci. 2013, 140, 62-69. [CrossRef] [PubMed]

61. Guthrie, H.D.; Welch, G.R. Determination of intracellular reactive oxygen species and high mitochondrial membrane potential in Percoll-treated viable boar sperm using fluorescence-activated flow cytometry. J. Anim. Sci. 2006, 84, 2089-2100. [CrossRef] [PubMed]

62. Martí, J.I.; Aparicio, I.M.; García-Herreros, M. Sperm morphometric subpopulations are differentially distributed in rams with different maturity age in cryopreserved ejaculates. Theriogenology 2011, 76, 97-109. [CrossRef]

63. Meyers, S.A. Sperm physiology. In Equine Breeding Management and Artificial Insemination; Samper, J.C., Ed.; Saunders Elsevier: Philadelphia, PA, USA, 2009; pp. 47-55.

64. Rodríguez-Martínez, H.; Kvist, U.; Ernerudh, J.; Sanz, L.; Calvete, J.J. Seminal plasma proteins: What role do they play? Am. J. Reprod. Immunol. 2011, 66, 11-22. [CrossRef] [PubMed]

65. Gadea, J.; Sellés, E.; Marco, M.A.; Coy, P.; Matás, C.; Romar, R.; Ruiz, S. Decrease in glutathione content in boar sperm after cryopreservation: Effect of the addition of reduced glutathione to the freezing and thawing extenders. Theriogenology 2004, 62, 690-701. [CrossRef] [PubMed]

66. Ortega-Ferrusola, C.; Martin Muñoz, P.; Ortiz-Rodriguez, J.M.; Anel-López, L.; Balao da Silva, C.; Álvarez, M.; de Paz, P.; Tapia, J.A.; Anel, L.; Silva- Rodríguez, A.; et al. Depletion of thiols leads to redox deregulation, production of 4-hydroxinonenal and sperm senescence: A possible role for GSH regulation in spermatozoa. Biol. Reprod. 2019, 100, 1090-1107. [CrossRef]

67. Catalán, J.; Papas, M.; Trujillo-Rojas, L.; Blanco-Prieto, O.; Bonilla-Correal, S.; Rodríguez-Gil, J.E.; Miró, J.; Yeste, M. Red LED light acts on the mitochondrial electron chain of donkey sperm and its effects depend on the time of exposure to light. Front. Cell Dev. Biol. 2020, 8, 588621. [CrossRef] [PubMed]

68. Estrada, E.; Rivera del Álamo, M.M.; Rodríguez-Gil, J.E.; Yeste, M. The addition of reduced glutathione to cryopreservation media induces changes in the structure of motile subpopulations of frozen-thawed boar sperm. Cryobiology 2017, 78, 56-64. [CrossRef] 
69. Estrada, E.; Rodríguez-Gil, J.E.; Rocha, L.G.; Balasch, S.; Bonet, S.; Yeste, M. Supplementing cryopreservation media with reduced glutathione increases fertility and prolificacy of sows inseminated with frozen-thawed boar semen. Andrology 2014, 2, 88-99. [CrossRef]

70. Ball, B.A.; Vo, A.T.; Baumber, J. Generation of reactive oxygen species by equine spermatozoa. Am. J. Vet. Res. 2001, 62, 508-515. [CrossRef] [PubMed]

71. Bilodeau, J.F.; Blanchette, S.; Gagnon, C.; Sirard, M.A. Thiols prevent H2O2-mediated loss of sperm motility in cryopreserved bull semen. Theriogenology 2001, 56, 275-286. [CrossRef]

72. Fridovich, I. Superoxide radical and superoxide dismutases. Annu. Rev. Biochem. 1995, 64, 97-112. [CrossRef] [PubMed]

73. Ighodaro, O.M.; Akinloye, O.A. First line defence antioxidants-superoxide dismutase (SOD), catalase (CAT) and glutathione peroxidase (GPX): Their fundamental role in the entire antioxidant defence grid. Alex. J. Med. 2018, 54, 287-293. [CrossRef]

74. Hammerstedt, R.H. Maintenance of bioenergetic balance in sperm and prevention of lipid peroxidation: A review of the effect on design of storage preservation systems. Reprod. Fertil. Dev. 1993, 5, 675-690. [CrossRef] [PubMed]

75. Holt, W.V. Mechanisms of sperm storage in the female reproductive tract: An interspecies comparison. Reprod. Domest. Anim. 2011, 46, 68-74. [CrossRef] [PubMed] 